\title{
32 \\ Thermal Enrichment by Stormwater: Application to an Urban Area with Shopping Mall and Treatment Wetland
}

\author{
Yi Li and William James
}

Thermal enrichment of receiving water bodies due to urban surface runoff has been recognized for some time as a potential threat to the aquatic environment, and many studies have repeatedly verified the effect (Pluhowski, 1970; Galli, 1990; Xie, 1993; Buren, 1999). However, thermal research on urban stormwater is basically still at an early stage, lacking theoretical and experimental support, especially the thermal behavior of shallow flow. In addition, a large number of variables are involved, causing many uncertainties, with the result that thermal modeling is not widely used. After reviewing four previous studies (Verspagen, 1995; Buren, 1999; Norman and Roa, 2000; Haq, 2001), Li (2003) concluded that, currently, two major problems should be explored more deeply: (i) runoff temperatures should be calculated using a heat balance analysis; (ii) a model for temperature of runoff from urban stormwater drainage systems should include at least four categories of basic hydraulic element: overland surface, enclosed pipe, open channel and pond. Attempting to solve the two problems, the authors built a model, called HEATRAN, that computes runoff temperature directly, using a distributed heat balance for the four types of hydraulic element in urban drainage systems.

Li, Y. and W. James. 2004. "Thermal Enrichment by Stormwater: Application to an Urban Area with Shopping Mall and Treatment Wetland." Journal of Water Management Modeling R220-32. doi: 10.14796/JWMM.R220-32.

(C) CHI 2004 www.chijournal.org ISSN: 2292-6062 (Formerly in Innovative Modeling of Urban Water Systems. ISBN: 0-9683681-9-0) 


\subsection{HEATRAN}

The central idea of HEATRAN is the combined heat balance and mass balance formulation for each of the various stormwater elements to be found in a typical drainage system. All flow behavior involved in urban stormwater drainage systems is generalized into a single description, and applied to four broadly similar flow situations:

1. overland flow,

2. closed conduit or pipe flow,

3. open channel flow, and

4. ponds and wetlands.

HEATRAN discretizes a watershed into these four categories of hydraulic element and connects them as a network. In this way, the methodology allows a HEATRAN model to be developed for an infinitely large and complex drainage network. The energy budget is analyzed for each element, covering the six principal heat transfer components for an open water body: inflow, outflow, rainfall, convection, evaporation (sensible heat), and net radiation.

Thermal energy introduced in, or transported out of, a water body by inflow, outflow, and rainfall during a given period is considered to be:

$$
V \cdot \rho \cdot c \cdot T
$$

a product of volume $(\mathrm{V})$, density $(\rho)$, specific heat $(\mathrm{c})$, and temperature $(\mathrm{T})$. In HEATRAN, observed data are used to estimate net radiation. The Mayer equation (Ponce, 1989) is used to estimate the evaporation rate, which leads to the calculation of heat loss by evaporation, while sensible heat is treated by using the Bowen ratio (Chow, 1964). Convection at the interface between the runoff water and the underlying material is governed by Newton's law of cooling, however the convective heat-transfer coefficient between runoff and the ground surface is one of the major uncertainties in this research. Its determination is difficult in many cases. In this work, dimensional analysis was used to derive general expressions of the convective heat-transfer coefficient for different hydraulic elements and conditions. The derived formulations are given in Table 32.1. The expressions include coefficients that can be calibrated against field data.

The dimensionless coefficients individually control effects of various terms in the expressions for the convection heat-transfer coefficients. For example, F1 and F1' control the coefficient in an overall sense; F3 and F4 control the effects of the Prandtl number and the Reynolds number, respectively; F11 controls the effect of hydraulic radius in overland flow; F16 controls 
Table 32.1 Summary of convective heat transfer coefficients.

\begin{tabular}{|c|c|c|}
\hline $\begin{array}{l}\text { Hydraulic } \\
\text { elements }\end{array}$ & Dry periods & Wet periods \\
\hline Pipe & ignored & \multirow{2}{*}{$h=F 1 \cdot \frac{k}{R_{h}} \cdot \operatorname{Pr}^{F 3}\left(\operatorname{Re}_{R}^{F 4}+F 2\right)$} \\
\hline Channel & \multirow{3}{*}{$h=F 5 \frac{k u}{v}\left(P r^{F 7}+F 6\right)$} & \\
\hline Subcatchment & & $\begin{array}{l}h=G 1 \cdot \frac{k}{R_{h}} \cdot \operatorname{Pr}^{F 3}\left(\operatorname{Re}_{R}^{F 4}+F 2\right) \\
\left.G 1=e^{\left(F 1+F 11 \cdot R_{h}+F 14|\operatorname{Tr}-T g| \cdot i^{F 16}\right.}\right)\end{array}$ \\
\hline Pond & & $h=F 1^{\prime} \frac{k}{d}\left(\operatorname{Pr}^{F 3^{\prime}}+F 2^{\prime}\right)$ \\
\hline \multirow{11}{*}{$\begin{array}{l}h \\
h \\
F \\
I \\
a \\
I \\
I \\
\nu \\
\nu\end{array}$} & \multicolumn{2}{|c|}{$h=$ convection heat-transfer coefficient $\left(W / m^{2} \cdot{ }^{\circ} \mathrm{C}\right)$} \\
\hline & \multicolumn{2}{|c|}{$k=$ thermal conductivity $\left(\mathrm{J} / \mathrm{kg} \cdot{ }^{\circ} \mathrm{C}\right)$} \\
\hline & \multicolumn{2}{|c|}{$R_{h}=$ fluid hydraulic radius $(\mathrm{m})$} \\
\hline & \multicolumn{2}{|c|}{$d=$ water depth of pond (m); } \\
\hline & \multicolumn{2}{|c|}{$\operatorname{Pr}=$ Prandtl number; } \\
\hline & \multicolumn{2}{|c|}{$R e_{R}=$ hydraulic radius-based Reynolds number; } \\
\hline & \multicolumn{2}{|c|}{$u=$ flow velocity $(\mathrm{m} / \mathrm{s})$} \\
\hline & \multicolumn{2}{|c|}{$v=$ fluid kinematic viscosity $\left(\mathrm{m}^{2} / \mathrm{s}\right)$} \\
\hline & \multicolumn{2}{|c|}{$\operatorname{Tr}=$ runoff temperature $\left({ }^{\circ} \mathrm{C}\right)$} \\
\hline & \multicolumn{2}{|c|}{$T g=$ ground surface temperature $\left({ }^{\circ} \mathrm{C}\right)$} \\
\hline & \multicolumn{2}{|c|}{$\mathrm{G} 1=\mathrm{a}$ dimensionless coefficient group whose form was determined empirically } \\
\hline
\end{tabular}

the effect of rainfall intensity in overland flow; F14 controls the effect of temperature difference between runoff and overland surface.)

Another important thermal process is conduction in the material underlying the runoff water, e.g. pavement, swale, stream bed, conduit, lake bottom, and so on, and which influences the temperatures of the underlying ground. The thermal process is treated as one-dimensional heat conduction in the vertical direction, and a finite difference method is employed to obtain numerical solutions. The runoff water is assumed to be completely mixed in every element, thus an overall heat and the mass balance is applied to obtain water temperatures for a single element at different times. 
Application of the heat and mass balance may encounter difficulties, because the temperature calculation for shallow and low flow in urban stormwater systems is very sensitive to external influences due to its small volume. Oftentimes, a simple summation of the above heat transfer components results in unreasonable water temperatures, as Haq (2001) experienced. Uncertainties make the problem hard to control. The heat and mass balance analysis employs many highly empirical equations (Meyer equation, Bowen ratio, and our newly-developed convection heat-transfer coefficients), and the applicability of these equations (especially the empirical parameters contained in these equations) to shallow and low flow in urban stormwater systems is uncertain. Although HEATRAN uses measured radiation data to estimate net radiation, the observations used for the first application of HEATRAN did not contain long-wave radiation. Furthermore, for simplification, the penetration of net radiation through the runoff water is ignored, thus neglecting solar heat flux absorbed by the ground surface, even though radiation can in reality reach some depth below the water surface (Fischer et al. 1979). Considering these uncertainties, a special incremental-step calculation approach was developed to control the high computational sensitivity of the low-flow condition, as well as to ensure continuity and stability of the results. The main principle of this approach is to ensure that no single heat transfer component in the heat budget will cause an unreasonable temperature change after a single time step in the temperature calculation. To implement the strategy, evaporation (plus sensible heat), net radiation and convection, which are important uncertain heat transfer components, are individually introduced to the mass and heat balance. The term used to describe this approach, incremental-step calculation, describes the systematic introduction of individual heat transfer processes. After a heat transfer component is introduced, if the resulting runoff temperature appears somewhat unreasonable, in a technical sense (exceeding a prescribed range from the temperature of the previous step), the thermal effect of this component is reduced by a prescribed fraction. This adjustment continues until the resulting runoff temperature becomes normal, not exceeding the prescribed range of variation. This methodology eliminates the troublesome computed excessive temperature changes, allowing HEATRAN to be applied to low flow.

Programmed in MatLab Version 5.3, HEATRAN comprises 18 subroutines. The general operational procedure for modeling runoff temperature in HEATRAN is as follows:

1. An external tool provides a discharge hydrograph for every hydraulic element. Here HEATRAN works with PCSWMM 2002, an urban drainage system model developed by CHI (James 
and James, 2000). The RUNOFF module is used for overland flows, TRANSPORT for pipe and channel flows, and STORAGE for ponds. One important limitation is that infiltration is ignored. Although unrealistic, this assumption is appropriate for impervious areas such as malls and parking lots.

2. Hydrographs provided by PCSWMM 2002 are transferred to HEATRAN using Microsoft Excel.

3. HEATRAN calculates runoff temperatures for all hydraulic elements using meteorological data as input, thus obtaining runoff temperatures everywhere in the watershed. HEATRAN performs three main functions:

1. transfer flow and temperature data at connections between elements, and create storage data for all elements; 2. back-calculate flow depths in subcatchments, pipes and channels;

3. calculate runoff temperatures by heat and mass balance.

\subsection{Application to Crossroads Mall}

\subsubsection{Project Background}

Our case study is the Consolidated Drain, located in the City of Portage, Michigan, USA. The Consolidated Drain is an open channel waterway, which drains approximately 188 ha (463 acres) of mixed residential and commercial lands into Portage Creek. Stormwater loadings from the drain have been identified as the largest single contributor of pollutants to Portage Creek within the City. The Consolidated Drain (and adjacent Schuring Drain) discharge to a section of Portage Creek designated as a cold water habitat where trout have historically been stocked by the State of Michigan (Kieser \& Associates, 2002a). The drainage areas for both drains form the Consolidated/Schuring Drain Watershed shown in Figure 32.1.

In addition to exacerbated pollutant/sediment loadings and flashy hydraulics from the Consolidated Drain watershed, thermally enriched stormwater has also been observed entering Portage Creek from Consolidated Drain. Initiated in 1999 by Kieser \& Associates, a thermal enrichment study targets a 5 y effort to evaluate and identify innovative and/or traditional approaches to moderate temperature impacts associated with urban stormwater runoff. Since May of 1999 a network of thermistors deployed throughout the Consolidated Drain and 


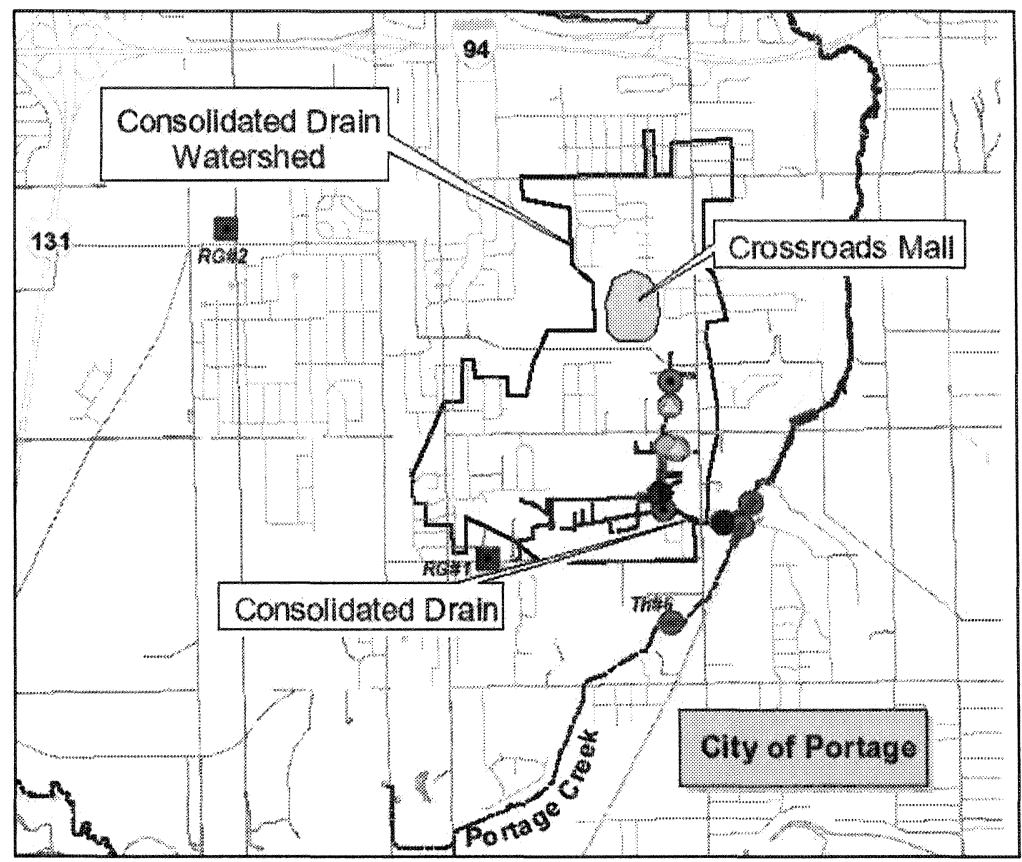

Figure 32.1 Consolidated/Schuring Drain Watershed (K\&A, 2002a).

upstream and downstream of the drain's confluence with Portage Creek has been monitoring water temperature at 5-min intervals. The data have shown significant thermal impacts on Portage Creek, and these have been attributed to stormwater from the Consolidated Drain (K\&A, 2002a).

In the Consolidated watershed, Crossroads Mall contributes a substantial portion of the thermally enriched stormwater to Consolidated Drain, due to its impervious surfaces. The total drainage area of the mall is 30 ha (76 acres) (K\&A, 2002a) or $16.4 \%$ of the Consolidated Watershed. The mall area is divided into two drainage areas: East area of 16 ha (39.5 acres) includes 11 pipes; West area of 14.8 ha (36.5 acres) includes 12 pipes. Stormwater from the East and West areas eventually drains into $\mathrm{MH}-10 \mathrm{~B}$ and $\mathrm{MH}-10 \mathrm{~A}$, respectively. From $\mathrm{MH}-10 \mathrm{~A}$, runoff from the West area is conveyed by two parallel pipes $1030 \mathrm{~mm}$ (42 in.) and $1470 \mathrm{~mm}$ (60 in.) to $\mathrm{MH}-10 \mathrm{~B}$, where the two flows merge. The merged stormwater is carried by two parallel pipes $1030 \mathrm{~mm}$ (42 in.) and 1470 $\mathrm{mm}$ (60 in.) to MH-9, and then to Overflow Weir \#2, which is connected to a $1030 \mathrm{~mm}$ (42 in.) pipe and the Consolidated Drain. 
In the portion of the Consolidated Drain watershed upstream of Overflow Weir \#2, surface runoff is collected by a pipe network whose pipe diameters range from $343 \mathrm{~mm}$ (14 in.) to $1620 \mathrm{~mm}$ (66 in.). Eventually the stormwater drains into a $1030 \mathrm{~mm}$ (42 in.) pipe at Overflow Weir \#1. The Consolidated Drain stormwater treatment facility (K\&A, 2002b), includes two conveyances from Overflow Weir\#1: (i) an open channel, the Consolidated Drain Floodway Channel, which is the upstream portion of the Consolidated Drain, and (ii) a $1030 \mathrm{~mm}$ (42 in.) pipe, which bypasses Overflow Weir \#2 to reach the sediment forebay. This portion of stormwater flows through the forebay, a wet detention facility and a series of wetlands, and finally into the Consolidated Drain. The former conveys flows larger than the 2-y event, while the latter is the regular conveyance.

\subsubsection{Modeling}

Currently, all simulation efforts for the Consolidated watershed are concentrated on the mall and adjacent areas, specifically the upstream portion from the sediment forebay. In total, there are 51 elements: 24 subcatchments and 27 pipes. Among the pipes, \#24 \#48 are concrete, while \#50 and \#51 are HDPE (high density polyethylene). All overland flow elements (subcatchments) are considered to be impervious. (This assumption may be not realistic for Part II, but the area calibration remedies this.) Since PCSWMM Transport can simulate only dendritic networks, the parallel pipes immediately below the mall (a bifurcation structure) were combined into three single pipes (\# 46, \#47 and $\# 48$ ). The equivalent diameters of these single pipes were determined by flow rate calibration.

The simulation approach is to:

1. use flow data at sites 25 and 26 (gauge: $\mathrm{f}-25 \mathrm{maru}$ ) to calibrate PCSWMM modeling of Part I; and flow data at site 28 (gauge: f-28seinis) to calibrate PCSWMM modeling of the combined watershed; thus obtaining flow data for every hydraulic element inside the whole watershed.

2. use temperature data at sites 25 and 26 (gauges: t-25maru.1, $\mathrm{t}$-26maru.2) to calibrate HEATRAN modeling of Part I; directly employ the temperature data at site 10 (gauge: $\mathrm{t}-10 \mathrm{he}$ ) for runoff from Part II; and use temperature data at site 28 (gauge: $\mathrm{t}$-28seinpi) to calibrate the overall HEATTRAN modeling. 


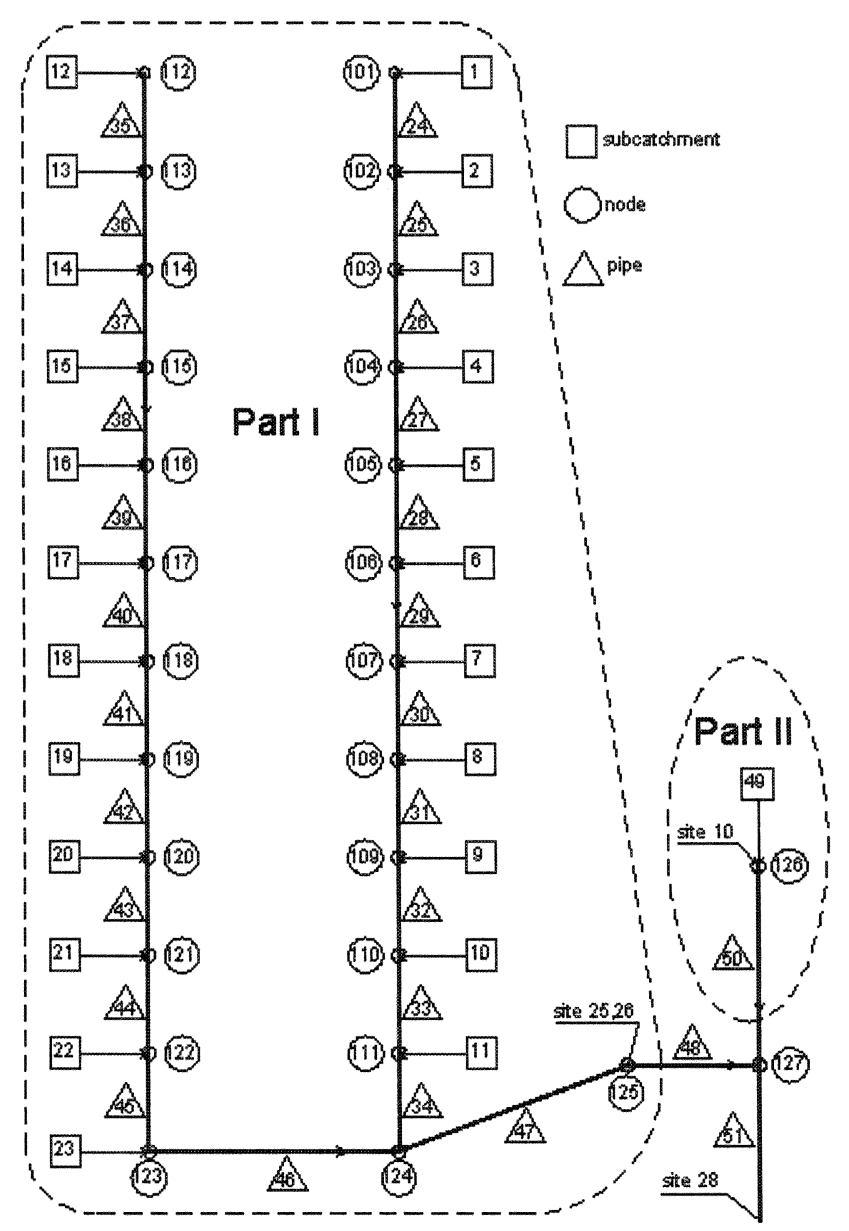

Figure 32.2 Discretization scheme for the Mall and adjacent areas.

Two storm events were chosen: July 29, 2002 and August 13, 2002. The total simulation period is $2 \mathrm{~h}$ for each event. In HEATRAN modeling, the time step was determined to be $30 \mathrm{~s}$; while the PCSWMM model used a 5-min time step.

Since no information on pavement structure and pipe installation is available, to simplify the situation, the underlying bodies of subcatchment and pipe elements were assumed to be uniform and constant as shown in Table 32.2. Pipe bedding was assumed to be sand around the circumference. 
Table 32.2 Profile of underlying bodies.

\begin{tabular}{cccc}
\hline Elements & Layers & Depth (m) & Material \\
\hline Subcatchment & Paving (top) & 0.1 & asphalt \\
& Subgrade (bottom) & 1.0 & gravel \\
\multirow{2}{*}{ Pipe } & Pipe wall (top) & 0.1 & concrete/HDPE \\
& Bedding (bottom) & 0.5 & sand \\
\hline
\end{tabular}

\section{PCSWMM simulation}

The simulation results are shown in Figures 32.3 and 32.4.

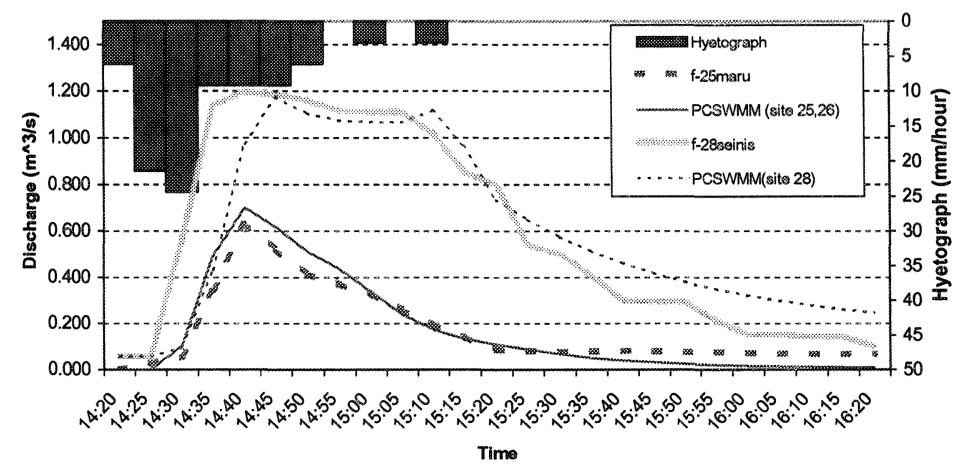

Figure 32.3 Discharge hydrograph (July 29).

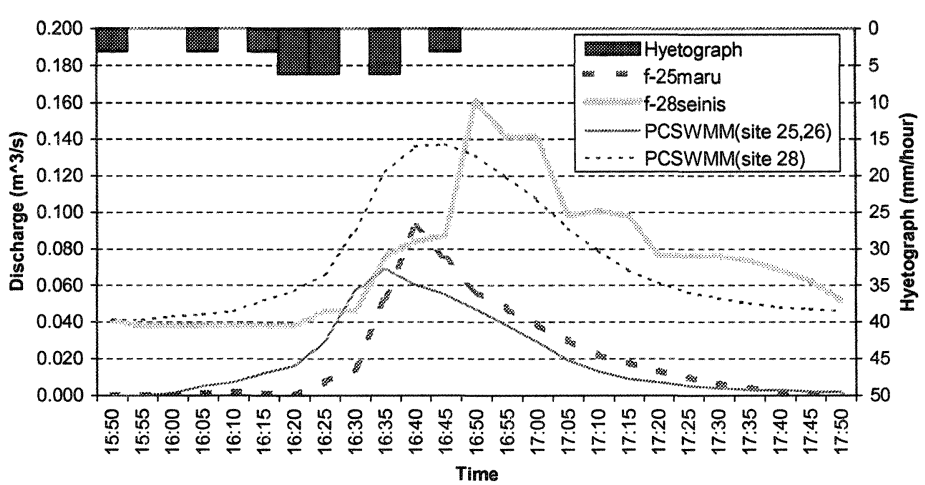

Figure 32.4 Discharge hydrograph (August 13). 


\section{HEATRAN simulation}

The HEATRAN model was run for the watershed system. Computed water temperatures are compared to the observed in Figures 32.5 to 32.8 . The results agree with the observed data in most situations, except at the beginnings where the observed flow rate might be too low to be captured by the gauge. Figures 32.9 and 32.10 illustrate the corresponding relationships between various temperatures, as well as the hyetograph and the flow discharge in pipe 47. (Note: temperature gauges $\mathrm{t}-25$ maru. 1 and $\mathrm{t}-26$ maru. 2 are positioned at the same location: sites 25 and 26.)

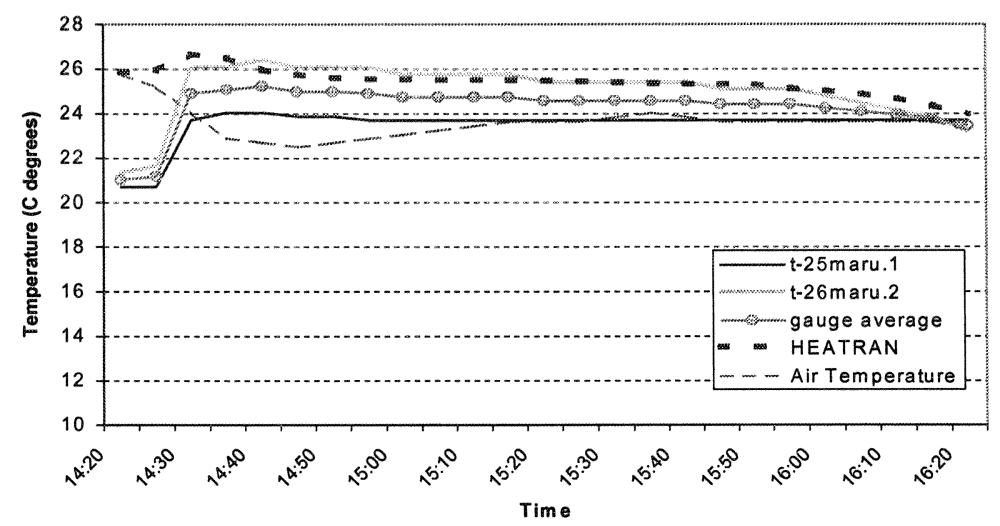

Figure 32.5 Runoff temperature comparison at sites 25 and 26 (July 29).

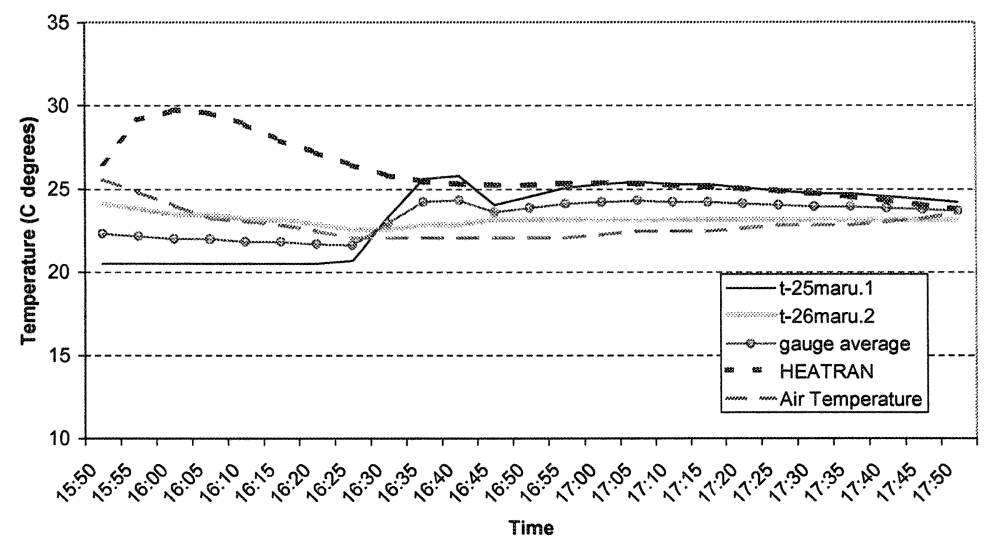

Figure 32.6 Runoff temperature comparison at sites 25 and 26 (August 13). 


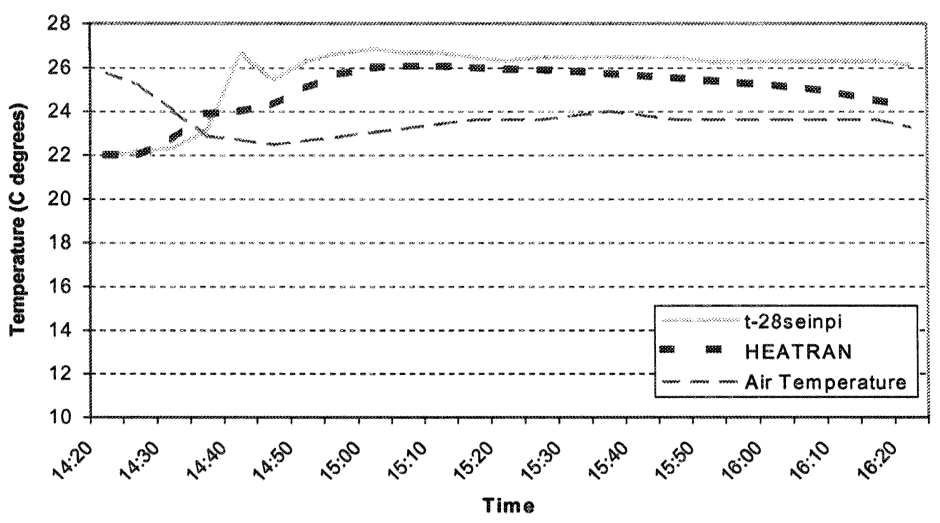

Figure 32.7. Runoff temperature comparison at site 28 (July 29).

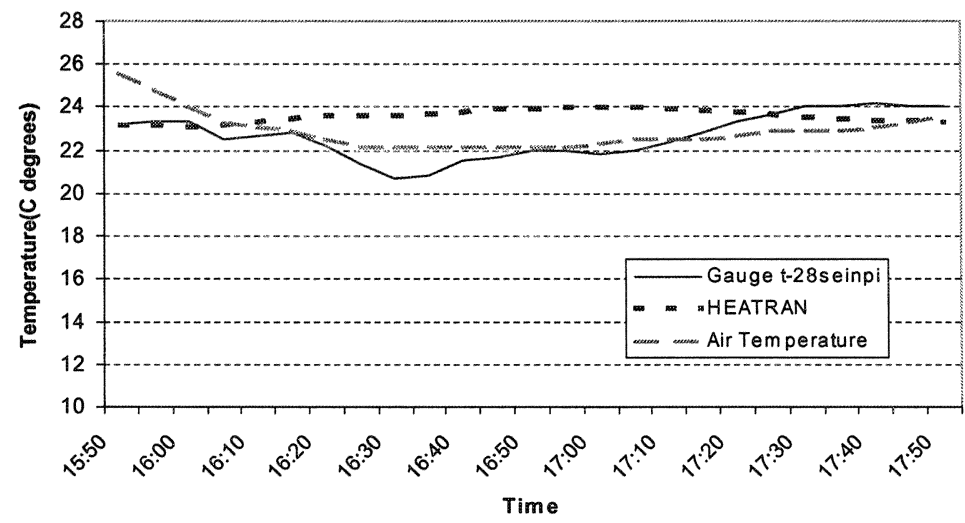

Figure 32.8 Runoff temperature comparison at site 28 (August 13).

\subsection{Discussion}

Sensitivity analysis shows that a flow-depth-related heat loss that occurs inside pipes is dominant in controlling the runoff temperature of pipes. This heat loss is evidently a seasonal effect, and an important term. Additionally, flow depth and rainfall intensity in the convection heat transfer coefficient for subcatchments are also important, and hence both are taken into consideration for the convection heat transfer coefficient for subcatchment elements. Solar radiation and evaporation were insensitive. 


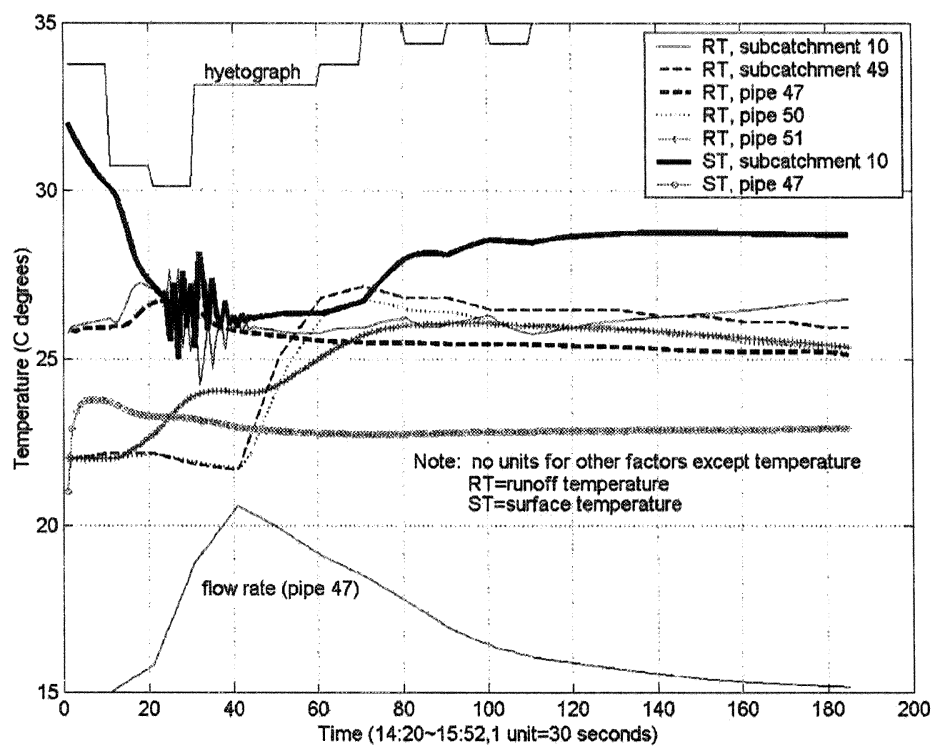

Figure 32.9 General demonstration of temperatures and relevant factors (July 29).

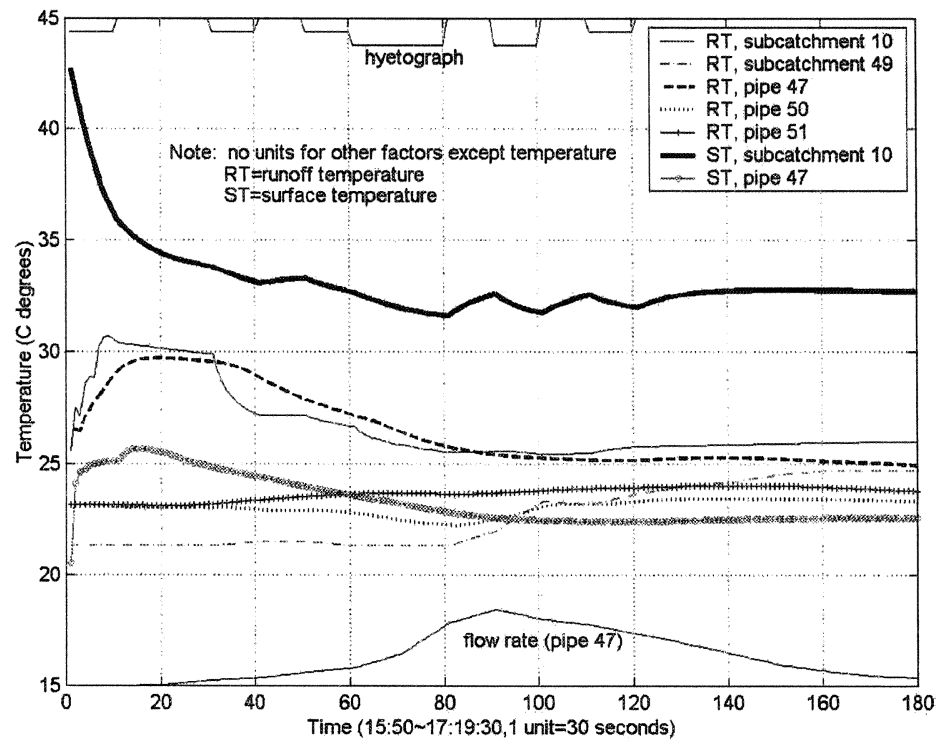

Figure 32.10 General demonstration of temperatures and relevant factors (August 13). 
At the beginning of the rain event, observed temperatures from $t-25$ maru. 1 and $t-26$ maru. 2 were usually lower than computed temperatures. The temperature gauges are above the low flow depths at the onset of a rain event, and thus measure the temperature of the pipe surface or of the air. Also, no flow may have yet occurred in the pipe at that time. On the other hand, since surface detention was ignored in PCSWMM modeling, PCSWMM produced minor and immediate flow changes and the theoretical calculation of HEATRAN also produces a temperature variation for the flow change at that time.

Except for the extreme low-flow periods at the beginning and the end of a wet event, the computed temperature at sites 25 and 26 is closer to t-26maru. 2 for the July 29 event (which had a relatively higher flow), while closer to t25maru.1 for the August 13 event (a relatively lower flow). Note that the abnormal drop of t-25maru. 1 in the August 13 event should be ignored. These observations supported the two descriptions for both gauges by Kieser and Associates (2002b): (i) "during mid to high flow, this thermistor (t-26maru.2) is inundated and is likely the most accurate of the two mall thermistors (25maru.1 and t-26maru. (ii) in measuring peak stormwater temperature during the event"; 2 . "during very low flow, this thermistor ( $t-26$ maru.2) may not be inundated". Thus, in the July 29 event, t-26maru. 2 probably functioned better, while in the August 13 event, probably only t-25maru.1 functioned. Thus we see that the HEATRAN resultsare supported by the correct gauge in each case.

When surface temperature and runoff temperature became close, both temperatures experience a period of abrupt fluctuations as shown in Figure 32.11. In this situation, numerical instability is the probable cause. Both event simulations progress through this period, eventually becoming normal, and the overall trends were not lost. The phenomenon reveals the sensitivity of the temperature calculation at low flows. Future work should be made to control excessive temperature changes of the ground surface, which in turn will smooth out the computed fluctuations over these periods.

Initial ground surface temperature for the event of August $13(42.7 \mathrm{oC})$ was much higher than for the event of July $29(320 \mathrm{C})$. Generally, however, lower runoff temperatures were recorded by t-25maru. 1 and $\mathrm{t}-26$ maru. 2 at sites 25 and 26 in the event of August 13. The principal cause of this inconsistency could be a smaller rainfall intensity and smaller total rainfall. This provides cogent evidence for the positive effect of flow depth and rainfall intensity on the convection heat transfer coefficient for overland flow elements.

For the subcatchment element, an interaction between rainfall, ground surface temperature and runoff temperature is clearly demonstrated in both events, as shown in Figures 32.9 and 32.10. In Figure 32.9, computed surface 
temperature gradually decreased from the onset of rain, as rainfall increased. Correspondingly, runoff temperature also rose by absorbing heat from the hot paving surface. Similarly, surface temperatures in event August 13 and runoff temperatures in both events experienced wave-like periods where they decreased during rainfall, and increased when rainfall stopped. These varying relations between the three indexes show the cooling effect of cooler rainfall on hotter surfaces.

For subcatchment elements, during dry periods, precisely after runoff drained off, computed surface temperature increased more or less gradually, because heat loss is smaller than during wet periods. Table 32.3 compares HEATRAN output to observed, and shows reasonable surface temperatures.

Table 32.3 Surface temperature comparison for the Mall.

\begin{tabular}{ccc}
\hline & July 29,2002 & August 13,2002 \\
\hline Period of rain event & $14: 20 \sim 16: 20$ & $15: 50 \sim 17: 50$ \\
Time of comparison & $15: 20 \sim 15: 32$ & $18: 00$ \\
Measured surface temperature & $28.2^{\circ} \mathrm{C} \sim 30.2^{\circ} \mathrm{C}$ & $29.6{ }^{\circ} \mathrm{C} \sim 34.1^{\circ} \mathrm{C}$ \\
Computed surface temperature* & $28.64^{\circ} \mathrm{C} \sim 28.75^{\circ} \mathrm{C}$ & $33.73^{\circ} \mathrm{C}$ \\
\hline
\end{tabular}

(*Note: the computed surface temperature is for subcatchment 10 only.)

Pipes have a cooling effect (negative thermal enrichment) on urban stormwater runoff in summer daytimes. In Figures 32.10 and 11, the runoff temperature of a subcatchment (element 10) is usually higher than the temperature inside pipes (element 47). The pipe environment is obviously cooler, probably because of zero solar radiation.

The water temperature in pipe 47 is higher than the air temperature in the both events. Rainfall temperature was taken to be the same as air temperature, following the findings of Norman and Roa (2000) who state that that air temperature is a good approximation to rain temperature for events prior to noon, and thus the heated runoff in pipe 47 is derived from the mall runoff, a large and typical parcel of urban development. This situation typifies thermal enrichment by urban stormwater runoff.

In the one-dimensional heat-conduction equation, for the coefficient of dispersion (diffusion) term, a higher thermal conductivity and lower specific heat can promote heat transfer between the ground and the runoff. Usually, the ground surface is hotter than rain in summer daytimes, transferring heat to the runoff. To control the thermal effect of urban runoff, ground surface materials with lower conductivity and higher specific heat may be preferable. 
For the various pipe materials, thermal conductivity and specific heat used in this research were:

1. HDPE: $0.45 \mathrm{~W} / \mathrm{m} /{ }^{\circ} \mathrm{C}$ and $2250 \mathrm{~J} / \mathrm{kg} /{ }^{\circ} \mathrm{C}$ (Typical properties of HDPE, Wiik \& Hoeglund Public Company Limited, Thailand, 2003); and

2. Concrete: $0.76 \mathrm{~W} / \mathrm{m} /{ }^{\circ} \mathrm{C}$ and $921 \mathrm{~J} / \mathrm{kg} /{ }^{\circ} \mathrm{C}$ (Holman, 1986).

HDPE has a lower convective heat transfer coefficient than concrete due to HDPE's lower thermal conductivity and higher specific heat. Often in summer daytimes, underground pipes are a cooler environment than open ground surfaces, and runoff from overland flow will lose heat inside the pipes. Therefore, a higher convective heat transfer coefficient will help to transfer more heat from the runoff to pipe wall, implying that concrete pipe might be a better choice in practice for thermal enrichment management.

Picksley and Deletic (1999) studied 91 events for two catchments, using a statistical method, and obtained three trends:

1. an overall decrease in runoff temperature during the event duration;

2. runoff temperature decreases most rapidly during discharge peaks;

3. a constant runoff temperature at the end of the event.

In our study, trends 1 and 3 are obviously observed, as seen in Figures 32.9 and 10. Except in a short increasing period, runoff temperature (especially in pipes) generally decreases more or less in both events, and basically remains constant and similar at the end. Both trends also show that radiation and evaporation did not dominantly contribute to the heat balance in overland runoff, as was also supported by the sensitivity analysis. For subcatchment elements, therefore, two heat transfer components become crucial: rainfall and convection. This conclusion also supports the viewpoint of Picksley and Deletic (1999) that all three trends depend on the volume of runoff and the magnitude of the temperature difference between the rainfall and the ground. Trend 2 was more evident in the event of August 13. In the July 29 event, probably due to the unstable fluctuations when the ground surface temperature and runoff temperature converged, this trend was not obvious.

\subsection{Conclusions}

As a deterministic and continuous temperature model, HEATRAN is reasonably efficient and computes temperature changes in a comprehensive way for a typical urban watershed. Working principles of HEATRAN are very clear, as development is concentrated on one only theme: the heat budget. Various heat 
transfer components are reasonably treated and combined. In particular, HEATRAN jointly calculates ground surface temperature and runoff temperature for stormwater drainage systems.

However, many uncertainties make modeling difficult. Due to the lack of information, some parameters must still be assumed, notably those for the underlying body of the elements. In addition, hydrographs used in HEATRAN are derived from PCSWMM, and the observed hydrograph from $\mathrm{f}-25 \mathrm{maru}$ was not used. The computed and observed flows are different. Moreover, the rainfall temperature and base flow are among the uncertain factors. Considering these uncertainties, a close match between computed and observed temperature will be difficult.

On the other hand, a critical period for watershed management when considering temperature impacts is during low-flow, warm summer periods and HEATRAN evidently handles low flow and small water volumes properly. This is most important.

In summary, several important conclusions may be drawn:

1 For subcatchments, rainfall and temperature difference between rainfall (or air) and ground surface are the two most important controlling factors for heat transfer processes during wet periods, while the effects of radiation and evaporation are limited.

2 For the convection heat transfer coefficient in subcatchments, rainfall intensity and flow depth have a positive effect.

3. For urban runoff thermal enrichment management, in terms of the convective heat transfer coefficient, materials with low conductivity and high specific heat are preferable for the land surface, and concrete might be a better material than HDPE for pipes. Light colored materials are also obviously better for flow surfaces.

4. The sewer network has a cooling effect (negative thermal enrichment) on urban runoff in summer daytimes. This point may lead to a management practice using pipe networks to reduce the thermal effect of urban runoff.

5. Several convection heat transfer coefficients are developed:

for paving in wet periods:

$$
\begin{aligned}
& \qquad h=\frac{k}{R_{h}} \cdot R e_{R} \cdot e^{\left(-13.5+5000 R_{h}+0.33 \cdot|\operatorname{Tr}-\operatorname{Tg}| \cdot i^{0.1}\right)} \\
& \text { for paving in dry periods: } \quad h=\frac{k u}{v} \operatorname{Pr}^{0.5}
\end{aligned}
$$


for concrete closed conduits in wet periods:

$$
h=0.001 \cdot \frac{k}{R_{h}} \cdot \operatorname{Pr}^{0.4} \cdot \operatorname{Re}_{R}{ }^{0.5}
$$

and, for HDPE closed conduits in wet periods:

$$
h=0.00001 \cdot \frac{k}{R_{h}} \cdot \operatorname{Pr}^{0.4} \cdot \operatorname{Re}_{R}^{0.5}
$$

Note that the equations for these coefficients are highly empirical. They may not be applicable to circumstances other than those at the Crossroads Mall, Portage Creek, MI, USA. Nevertheless, they may form a useful starting point for similar future investigations.

\section{References}

Buren, M.A.V. (1999) Thermal enhancement of urban receiving waters. $\mathrm{PhD}$ dissertation, Department of Civil Engineering, Queen's University, Kingston, Ontario. 199 pages.

Chow, V.T. (1964) Handbook of Applied Hydrology. McGraw-Hill, Inc. pp: 11-12.

Fischer, H.B., List, E.J., Koh, R.C.Y., Imberger, J., and Brooks, N.H. (1979) Mixing in Inland and Coastal Waters. Academic Press, Inc. (London) Ltd. 164-165.

Galli, J. (1990) Thermal Impacts Associated with Urbanization and Stormwater Management Best Management Practices. Metropolitan Washington Council of Governments, Washington, D.C. pp: 157.

Haq, R.U. (2001) Thermal enhancement of stream temperature by urban stormwater in Portage Creek, MI. MEng thesis, School of Engineering, University of Guelph, Guelph, Ontario. 103 pages.

Holman, J.P. (1986) Heat Transfer. McGraw Hill, Toronto. 676 pages.

James, W. and James, R. (2000) Water Systems Models Hydraulics/A Guide to the Extran, Transport and Storage Treatment Modules of the USEPA SWMM4. CHI, Guelph, Canada.

James, W. and James, W.R.C. (2000) Water Systems Models Hydrology/A Guide to the Rain, Temperature and Runoff Modules of the USEPA SWMM4. CHI, Guelph. Canada.

Kieser and Associates (K\&A) (2002a) Information sheets. (by e-mail, express mail or website: http://www.kieser-associates.com)

Kieser and Associates (K\&A) (2002b) Progress Report \#4, Stormwater Thermal Enrichment in Urban Watersheds.

$\mathrm{Li}, \mathrm{Y}$. (2003) Thermal enrichment by urban stormwater of receiving water systems. MSc thesis, School of Engineering, University of Guelph, Guelph, Ontario. 151pp. 
Norman J.M. and Roa, A. (2000). Modeling the Effects of the Natural Environmental and Urban Runoff on Stream Temperature, Final Report. June 22, 2000.

Picksley, W. and A. Deletic. 1999. "The Thermal Enrichment of Storm Runoff from Paved Areas - a Statistical Analysis." Journal of Water Management Modeling R204-07. doi: 10.14796/JWMM.R204-07.

Pluhowski, E.J. (1970) Urbanization and Its Effect on the Temperature of the Streams on Long Island, New York. U.S. Geological Survey Professional Paper 627-D. pp: D1-D59.

Ponce, V.M. (1989) Engineering Hydrology: Principles and Practices. Prentice-Hall, Inc. pp: $42-44$

Typical properties of HDPE, Wiik \& Hoeglund Public Company Limited, Thailand. $<$ http://www.wiik-hoeglund.com/products/hdpe.html> (March, 2003).

Verspagen, B. (1995) Experimental Investigation of Thermal Enrichment of Storm Water Runoff from Two Paving Surfaces. MSc Thesis, School of Engineering, University of Guelph, Guelph, Ontario. 163 pages.

Xie, D.M. (1993) Modelling Solar Thermal Enrichment of Streams Due to Urban Storm Water. MSc Thesis, School of Engineering, University of Guelph, Guelph, Ontario. 118 pages. 